\title{
O uso de fitoterápicos orientais nas lesões renais: revisão integrativa
}

KUBA, G.1*; VATTIMO, M.F.F.1

Universidade de São Paulo - USP - Laboratório Experimental de Modelos Animais (LEMA) da Escola de Enfermagem, Av Enéas Carvalho de Aguiar, 419, CEP: 05403-000 - Sao Paulo, SP - Brasil *Autor para correspondência: gisele.kuba@gmail.com

\begin{abstract}
RESUMO: As disfunções renais constituem um problema de saúde global com alta prevalência e custos com internações hospitalares. A fitoterapia chinesa possui tradição milenar na prevenção e tratamento dessas disfunções e conta com o incentivo da OMS às práticas integrativas e complementares; o número de pesquisas experimentais cresceu substancialmente. Esta revisão tem como objetivo levantar os estudos que relacionem o tratamento das disfunções renais com fórmulas fitoterápicas pertencentes à medicina tradicional chinesa; identificar os modelos de lesão renal adotados, as ervas e as doses empregadas, bem como a eficácia do tratamento. Os artigos foram selecionados nas bases Pubmed e Lilacs com os seguintes termos: medicina tradicional chinesa, rim, e erva, em modelos animais no período de 10 anos. Foram selecionados 12 estudos sendo que em 11 o fitoterápico conseguiu prevenir ou melhorar a lesão renal; em 6 estudos foram utilizadas fórmulas contendo associação de plantas; e em outros 6 , o medicamento alopático foi o controle. Os modelos de lesão mais utilizados foram de nefrectomia e nefrotoxicidade enquanto a administração foi a via gavagem. A fitoterapia pode atuar como terapia complementar no tratamento das lesões renais, possui baixo custo e pode ser associado a intervenções alopáticas. Porém, é preciso conhecer profundamente os riscos, as possíveis interações, a toxicidade, e os mecanismos de ação, além dos possíveis efeitos adversos do uso dessas ervas.
\end{abstract}

Palavras-chave: Fitoterapia chinesa, lesões renais, modelos animais, Práticas integrativas e complementares.

\begin{abstract}
The use of oriental herbal medicines in acute kidney injury: an integrative review. Kidney dysfunction consists in a global healthcare problem with high prevalence and hospitalization costs. Chinese phytotherapy is part of ancient tradition used to treat and prevent renal injury. As a result of WHO incentives for integrative and complementary practices, the number of experimental researches has increased substantially. The aim of this review is to make a survey of studies that related traditional Chinese medicine, phytotherapy and kidney injuries; and identify methodology, plants, doses and their efficacy. Articles were selected using Pubmed and Lilacs database with the following terms: traditional Chinese medicine, kidney and in animal models for a period of 10 years. In 11 of the 12 studies selected, Chinese herbal medicine could prevent or improve kidney disease. 6 researches used combined herbs formulas and in the other 6 ones allopathic medicine were the control group; nephrectomy and nephrotoxicity were the most frequently used lesion models and the medicines administration was through oral gavage method. Phytotherapy can be used as a complementary therapy in kidney injuries treatments, shows low cost and can be associated with allopathic therapies. However it is necessary to know the risks, interactions, toxicity, mechanisms of action and adverse effects of medicinal plants.
\end{abstract}

Keywords: Chinese phytotherapy, kidney diseases, animal models, Integrative and complementary practices.

\section{INTRODUÇÃO}

As práticas integrativas e complementares podem ser definidas como um conjunto de terapias que visa à prevenção e promoção da saúde por meio de uma abordagem holística e integral do ser humano. Segundo a Política Nacional de Práticas Integrativas e Complementares (PNPIC),

Recebido para publicação em 12/11/2014 
tais práticas buscam estimular os mecanismos naturais de prevenção e recuperação da saúde por meio de tecnologias eficazes e seguras, com base na abordagem acolhedora, visão ampliada do processo saúde-doença e a promoção global do cuidado humano, integrando-o com o meio ambiente e a sociedade. A prevalência do uso das terapias complementares no mundo varia de 9,8 a $76 \%$. (Andrade \& Costa, 2010; Brasil, 2006; Harris et al, 2012).

O aumento na divulgação e difusão dessas práticas foi incentivado pela Organização Mundial da Saúde (OMS), a partir da criação de estratégias sobre a Medicina Tradicional. Segundo o órgão, a inclusão das terapias complementares possibilita aos países mais pobres o acesso a tratamentos mais baratos e que tenham relação com a sociedade que esses indivíduos estão inseridos. Porém essas práticas devem ser bem fundamentadas, seguras e eficazes (Who, 2002).

A Medicina Tradicional Chinesa (MTC) possui tradição milenar no uso da fitoterapia. Sua prescrição é fundamentada no diagnóstico holístico característico da filosofia oriental. Porém apesar da vasta experiência, as sinergias, doses e indicações possuíam um caráter empírico e a composição química, toxicidade, relação causa-efeito dessas ervas ainda precisam ser esclarecidas (Shao \& Zang, 2013).

A evolução tecnológica, maior difusão e interesse das técnicas orientais no mundo recentemente propiciaram o desenvolvimento de pesquisas com o objetivo de elucidar os efeitos e mecanismos de ação de ervas e fórmulas chinesas sobre diversas doenças (Yao et al, 2013).

As disfunções renais se enquadram nas alterações de uma estrutura denominada Shen pela MTC. Segundo a teoria oriental, é no Shen que a energia essencial ou Jing Qi reside e a partir desta energia que as heranças genéticas são transmitidas e ocorre a formação das substâncias vitais como sangue, líquidos corpóreos e Qi, necessários para a manutenção da homeostase. A redução dessa energia desencadeia os processos decorrentes do envelhecimento como enbranquecimento capilar, fragilidade óssea e diminuição da acuidade auditiva; enquanto que o seu esgotamento leva à morte (Maciocia, 2007). A intervenção com acupuntura e medicamentos fitoterápicos visa à preservação da energia do Shen.

A prevenção pelo diagnóstico e tratamento precoces também figura como meta principal nas principais associações de nefrologia (Tao et al, 2013). ). As lesões renais crônicas e agudas constituem um problema de saúde global, sendo responsáveis pelo aumento da morbidade, mortalidade e internações hospitalares. (Coca et al, 2009).

A lesão renal pode ser identificada por vários parâmetros, sendo a caracterizada pela dosagem de sérica de creatina, volume urinário e proteinúria (Huang et al, 2011). Pesquisas experimentais recentes em modelos animais estão utilizando como possíveis sinalizadores de lesão renal as análises morfológicas, histopatológicas, presença de mediadores inflamatórios nos tecidos renais e alterações no sistema renina angiotensina II. (Tao et al, 2013).

A literatura chinesa descreve diversas ervas para o tratamento das enfermidades renais (Lo, 2008). Por isso, o interesse na comprovação científica a respeito dos efeitos, dose e mecanismos de ação dos fitoterápicos aumentou consideravelmente. Diversos estudos com modelos animais são publicados anualmente colaborando para a elucidação e aproximação medicina tradicional chinesa com a medicina praticada no ocidente (Li et al, 2010; Lam \& Sun, 2013).

Portanto, os objetivos desta revisão foram os de identificar estudos que relacionem a medicina tradicional chinesa com fitoterapia em lesões renais e verificar quais são os métodos mais empregados, as ervas mais utilizadas, doses e os resultados obtidos.

\section{METODOLOGIA}

A pesquisa dos artigos foi feita a partir dos bancos de dados online Pubmed, ferramenta de pesquisa da base Medline (Medical Literature, Analysis and Retrieval System Online) e Lilacs (Literatura Latino-americana e do Caribe de Informação em Ciências da Saúde).

Os termos escolhidos foram: traditional chinese medicine, kidney, herbal no Pubmed e em português na base Lilacs: medicina tradicional chinesa, rim e erva. . A busca se limitou ao período de 10 anos.

A partir dos cruzamentos, observou-se a ocorrência de 478 artigos no total. Foram incluídos apenas os artigos com texto integral disponível em português, inglês ou espanhol e apenas realizados em animais restando 141 estudos. Foram excluídos 76 artigos que, apesar de possuírem os unitermos escolhidos, não relacionavam o tratamento de lesões renais com ervas e medicina tradicional chinesa e 36 estudos que utilizavam somente o principio ativo das plantas, 4 revisões e 14 estudos in vitro. Ao final da triagem, restaram 12 artigos que contemplavam os critérios de inclusão e exclusão. O fluxograma abaixo representa as etapas de seleção dos estudos. 


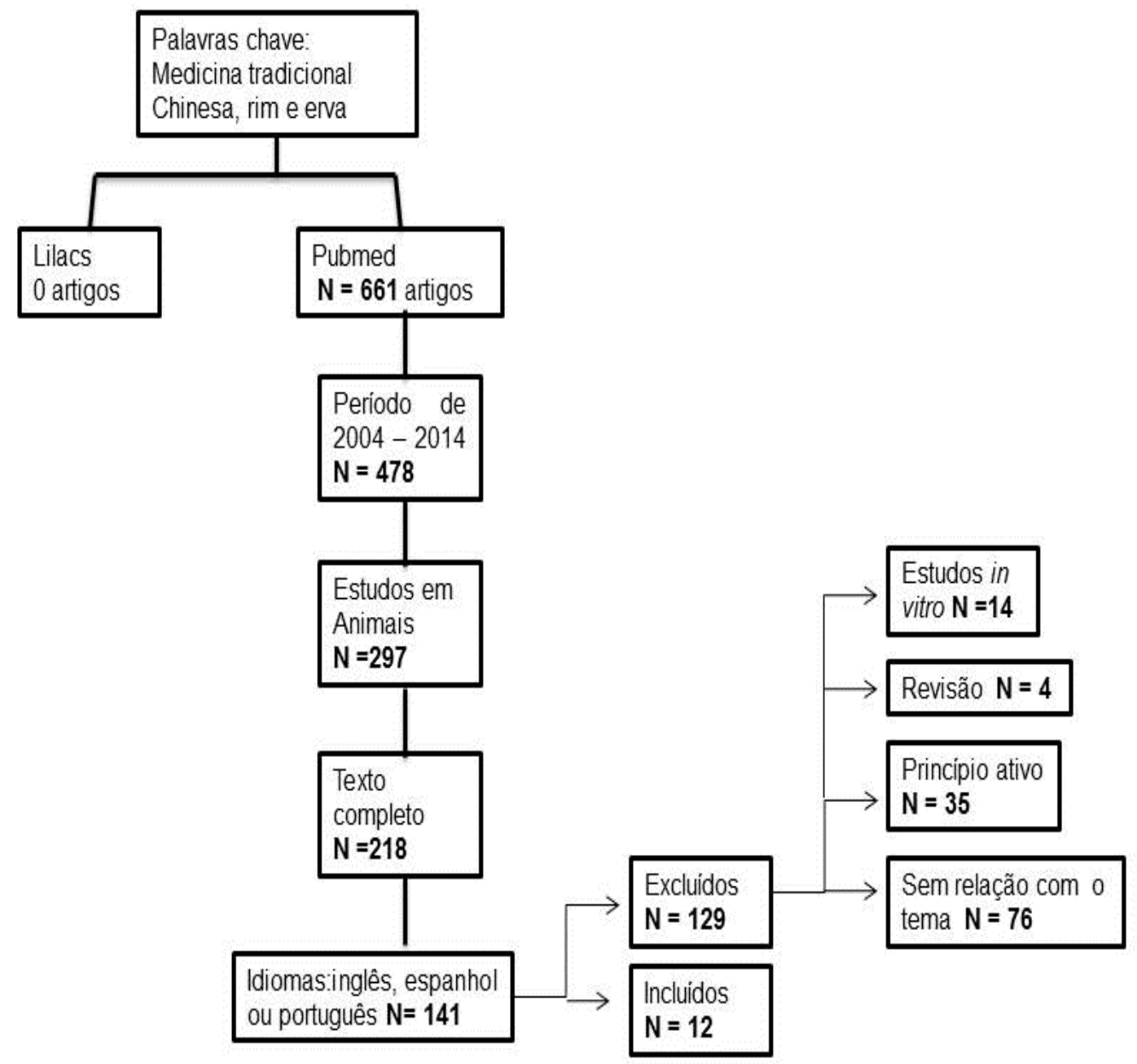

FIGURA 1. Fluxograma representando a seleção dos estudos incluídos na revisão.

\section{RESULTADOS}

Os 12 estudos foram selecionados segundo autor e ano, fitoterápico e drogas utilizadas, tipo de lesão renal, a metodologia empregada nos estudos, os principais parâmetros e os resultados obtidos (Tabela 1).

\section{DISCUSSÃO}

Com relação às ervas e medicamentos utilizados, apenas as ervas Astragalus membranaceus, Alisma orientalis, Rehmannia glutinosa, Poria cocos, Paeonia suffruticosa e Cinnamomum cassia se repetiram nos estudos.

Metade dos estudos utilizou as ervas em associação. He et al (2012) obtiveram resultados favoráveis com a combinação de Alisma orientalis, Poria cocos, Polyporus umbellatus, Atractylodes macrocephala e Cinnamomum cassia na nefrotoxicidade induzida por adriamicina. A melhora foi atribuída à modulação do sistema renina angiotensina e pela expressão gênica da nefrina.

As fórmulas herbais seguem os princípios de tratamento holístico e métodos de sinergia. A erva principal (imperatriz) trata a síndrome ou disfunção; a erva secundária (ministra) auxilia a principal promovendo o efeito curativo; a erva adjuvante modula as duas anteriores, minimizando a toxicidade e aumentando o efeito. A erva mensageira atua como harmonizadora, melhorando as funções dos demais componentes da fórmula (Sucher, 2013). Entretanto, com o advento da tecnologia, alguns autores objetivam identificar os princípios ativos responsáveis pela promoção dos efeitos benéficos. Erwei et al (2012) no seu estudo com a casca de Eucommia ulmoides apontou as substâncias Geniposide e genipina como responsáveis pela inibição de óxido nítrico e consequente redução de estresse oxidativo induzido por cádmio nos rins de ratos.

A publicação em revistas especializadas de maior impacto e a necessidade de sugerir metodologias que se adequem ao pensamento global da MTC, pode explicar o aumento na complexidade das pesquisas realizadas na China. Yang, et al (2013) em sua revisão dos progressos 
TABELA 1. Resumo da pesquisa relacionando lesão renal, ervas e medicina chinesa.

\begin{tabular}{|c|c|c|c|c|c|}
\hline $\begin{array}{l}\text { Autor e } \\
\text { Ano }\end{array}$ & $\begin{array}{l}\text { Fitoterápicol } \\
\text { droga }\end{array}$ & Lesão Renal & Metodologia empregada & Parâmetros relevantes & Resultados \\
\hline $\begin{array}{l}\text { He et al } \\
(2008)\end{array}$ & Wulingsan & $\begin{array}{l}\text { Nefrotoxici- dade } \\
\text { adriamicina (ADR) } \\
5 \mathrm{mg} / \mathrm{kg}\end{array}$ & $\begin{array}{l}\text { Gavagem: } 28 \text { dias Ratos Sprague-Dawley } \\
\text { Controle: (saudáveis) água destilada. } \\
\text { ADR controle: água destilada } \\
\text { ADR+WLS: } 120 \mathrm{mg} / \mathrm{kg} \\
\text { ADR+WLS: } 480 \mathrm{mg} / \mathrm{kg} \text {. }\end{array}$ & $\begin{array}{l}\text { ATPase; } \mathrm{Na}+, \mathrm{K}+, \mathrm{GSH} ; \\
\text { CAT;Creatinina, ureia } \\
\text { sérica; Histopatologia } \\
\text { renal, } \\
\text { Index renal\% }\end{array}$ & $\begin{array}{l}\text { WLS 480mg: melhora } \\
\text { nefrotóxicicidade pela } \\
\text { modulação do sistema } \\
\text { renina angiotensina renal } \\
\text { e da expressão gênica } \\
\text { da nefrina. }\end{array}$ \\
\hline $\begin{array}{l}\text { Erwei et al } \\
(2012)\end{array}$ & $\begin{array}{l}\text { Casca de } \\
\text { Eucommia } \\
\text { ulmoides }\end{array}$ & $\begin{array}{l}\text { Nefrotoxicida- de } \\
\text { cádmio } \\
1,0 \mathrm{mg} / \mathrm{kg}\end{array}$ & $\begin{array}{l}\text { Gavagem :5 dias Ratos Sprague Dawley } \\
\text { Normal: água destilada } 0,5 \mathrm{ml} / 100 \mathrm{~g} \\
\text { Controle: } 5 \% \text { de solução } 0,5 \mathrm{ml} / 100 \mathrm{~g} \\
\text { Controle+: vitamina E [500 mg/kg] } \\
\text { Baixa dose: E. ulmoides }[125 \mathrm{mg} / \mathrm{kg}] \\
\text { Dose média: E.ulmoides }[250 \mathrm{mg} / \mathrm{kg}] \\
\text { Dose Alta: E. ulmoides }[500 \mathrm{mg} / \mathrm{kg}]\end{array}$ & $\begin{array}{l}\text { ATPase; } \mathrm{Na}+, \mathrm{K}+ \\
\text { GSH; CAT; Creatinina, } \\
\text { uréia sérica; } \\
\text { Histopatologia renal } \\
\text { Index renal\% }\end{array}$ & $\begin{array}{l}\text { Efeito protetor contra } \\
\text { o dano oxidativo. } \\
\text { Geniposide e genipina } \\
\text { foram encontradas no } \\
\text { sangue e tecido renal e } \\
\text { inibiram a produção de } \\
\text { óxido nítrico (NO). }\end{array}$ \\
\hline $\begin{array}{l}\text { Gao } \\
\text { et al } \\
(2010)\end{array}$ & $\begin{array}{l}\text { Ruibarbo } \\
\text { Sinvastatina }\end{array}$ & $\begin{array}{l}\text { Nefropatia } \\
\text { Diabética (Ratos } \\
\text { C57BL/K e db/db) }\end{array}$ & $\begin{array}{l}\text { Gavagem:12 sem } \\
\text { A) } \mathrm{db} / \mathrm{m}+\text { salina (controle) } \\
\text { B) } \mathrm{db} / \mathrm{db}+\text { salina (controle); } \\
\text { C) } \mathrm{db} / \mathrm{db}+\text { rheum }[150 \mathrm{mg} /(\mathrm{kg} / \mathrm{d})] \\
\text { D) } \mathrm{db} / \mathrm{db}+\text { sinvastatina }[20 \mathrm{mg} /(\mathrm{kg} / \mathrm{d})] \text {. }\end{array}$ & $\begin{array}{l}\text { Albumina urinária; } \\
\text { ApoE; TGF- } \beta \text {; } \\
\text { Fibronectina }\end{array}$ & $\begin{array}{l}\text { Efeito nefroprotetor na } \\
\text { nefropatia diabética. } \\
\text { Meio de atuação distinto } \\
\text { ao da sinvastatina. }\end{array}$ \\
\hline $\begin{array}{l}\text { Wu } \\
\text { et al } \\
(2012)\end{array}$ & $\begin{array}{c}\text { Macrothelypteris } \\
\text { oligophlebia (EMO) }\end{array}$ & $\begin{array}{l}\text { Nefrotoxici dade } \\
\text { por Gentamicina } \\
100 \mathrm{mg} / \mathrm{kg}\end{array}$ & $\begin{array}{l}\text { Gavagem:8 dias } 2 \text { horas antes injeção } \\
\text { GM. } \\
\text { Grupo I: controle salina } \\
\text { Grupo II: GM intraperitonial } \\
\text { Grupo III: GM + EMO } 250 \mathrm{mg} / \mathrm{kg} \\
\text { Grupo IV:GM + EMO } 500 \mathrm{mg} / \mathrm{kg}\end{array}$ & $\begin{array}{l}\text { Ureia; Creatinina sérica; } \\
\text { MDA; NO; SOD; } \\
\text { CAT; (GSH -px) } \\
\text { Histopatologia. }\end{array}$ & $\begin{array}{l}\text { Significante efeito } \\
\text { nefroprotetor }\end{array}$ \\
\hline $\begin{array}{l}\text { Chan } \\
\text { et al } \\
(2013)\end{array}$ & Hachimi \& Bakumi & $\begin{array}{l}\text { Nefrectomia total } \\
\text { do rim direito e } \\
\text { secção de } 2 / 3 \text { do } \\
\text { rim esquerdo }\end{array}$ & $\begin{array}{l}\text { Gavegem por } 10 \text { sem Ratos Wister } \\
\text { Grupo Sham } \\
\text { Grupo controle: água destilada } \\
\text { Hachimi -jio- gan: } 150 \mathrm{mg} / \mathrm{kg} / \mathrm{dia} \\
\text { Bakumi -jio- gan: } 150 \mathrm{mg} / \mathrm{kg} / \mathrm{dia}\end{array}$ & $\begin{array}{l}\text { Cr e ureia; SOD, MDA; } \\
\text { CAT, GSH; GSSG; } \\
\text { Proteina e creatinina } \\
\text { urinária clearance de } \\
\text { creatinina.Histopatologia; } \\
\text { SOD e BARS;NF-kB65, } \\
\text { Nrf2, PPARa, SREBP-1, } \\
\text { SREB }\end{array}$ & $\begin{array}{l}\text { Melhora no estresse } \\
\text { oxidativo. Bakumi -jio- } \\
\text { gan obteve efeitos } \\
\text { antioxidantes maiores } \\
\text { que Hachimi }\end{array}$ \\
\hline $\begin{array}{l}\text { Yue } \\
\text { et al } \\
(2013)\end{array}$ & Huangkui (HCK) & $\begin{array}{l}\text { Nefrectomia } \\
\text { rim Direito e } \\
\text { nefrotoxicidade } \\
\text { adriamicina } \\
5 \mathrm{mg} / \mathrm{kg}\end{array}$ & $\begin{array}{l}\text { Gavagem : } 4 \text { sem Sprague-Dawley } \\
\text { Sham: água destilada } 2 \mathrm{ml} / \mathrm{dia} \\
\text { Veículo: água destilada } 2 \mathrm{ml} / \mathrm{dia} \\
\text { Dose alta HKC: }[2 \mathrm{~g} / \mathrm{kg} / \mathrm{dia}] \\
\text { Dose baixa HCK: }[0,5 \mathrm{~g} / \mathrm{kg} / \mathrm{dia}]\end{array}$ & $\begin{array}{l}\text { Histopatologia renal; } \\
\text { Proteinúria; Albumina, } \\
\text { ureia e creatinina sérica; } \\
\text { TNF- } \alpha \text { e i (IL)- } \\
\text { 2;p38MAPK e TGF- } \beta 1\end{array}$ & $\begin{array}{l}\text { HKC: melhora pela } \\
\text { redução da infiltração e } \\
\text { ativação de macrófagos } \\
\text { e da supressão da TNF- } \alpha \\
\text { renal e supressão da } \\
\text { TGF- } \beta 1 \text { e p-p38MAPK. }\end{array}$ \\
\hline $\begin{array}{l}\text { Chen et } \\
\text { al (2013) }\end{array}$ & $\begin{array}{l}\text { Yishen Huanji \& } \\
\text { Losartan }\end{array}$ & $\begin{array}{l}\text { induzida } \\
\text { por exercício) }\end{array}$ & $\begin{array}{l}\text { Gavagem: } 8 \text { sem Sprague-Dawley } \\
\text { COM = dieta } \\
\text { TRA }=\text { corrida tradicional } \\
\text { MOD }=\text { indução por exercício. } \\
\text { LOS }=\text { MOD + LOS }[20 \mathrm{mg} / \mathrm{kg}] \\
\text { CHI = MOD + YHD }[2 \mathrm{ml} / \mathrm{dia}]\end{array}$ & $\begin{array}{l}\text { Peso, hematúria, } \\
\text { N-acetyl-b-D- ; NAG } \\
\text { urina;Proteína e } \\
\text { albumina urinária,ureia } \\
\text { e creatinina;Níveis de } \\
\text { angiotensina II renal e no } \\
\text { plasma; AT1R no tecido } \\
\text { renal }\end{array}$ & $\begin{array}{l}\text { Losartan e Yishen } \\
\text { Huanji obtiveram efeito } \\
\text { renoprotetor no pós- } \\
\text { exercício. Yishen obteve } \\
\text { ação no sistema renina } \\
\text { angiotensina. }\end{array}$ \\
\hline $\begin{array}{l}\text { Wen et } \\
\text { al } \\
(2013)\end{array}$ & $\begin{array}{l}\text { Yiqiyangyin \& } \\
\text { Predinisona }\end{array}$ & $\begin{array}{l}\text { nefrotoxicidade } \\
\text { adriamicina } \\
5 \mathrm{mg} / \mathrm{kg}\end{array}$ & $\begin{array}{l}\text { Na ração: } 28 \text { dias Sprague -Dawley } \\
\text { Controle: saudáveis } \\
\text { Modelo: sem intervenção } \\
\text { Predinisona: }[5 \mathrm{mg} / \mathrm{kg} \text { dia] } \\
\text { Fito: }[6.2 \mathrm{~g} / \mathrm{kg} \text { dia] } \\
\text { Fito + Predinisona: }[6.2 \mathrm{~g} / \mathrm{kg}] \text { e }[5 \mathrm{mg} / \mathrm{kg} \\
\text { dia] }\end{array}$ & $\begin{array}{l}\text { Proteinúria;Creatinina } \\
\text { e albumina sérica } \\
\text {;Histopatologia renal; } \\
\text { PCR heparenase e } \\
\text { nefrina } \\
\text { Concentração de } \\
\text { heparenase urinária. }\end{array}$ & $\begin{array}{l}\text { Yiqiyangyin: reduziu } \\
\text { proteinúria,melhores } \\
\text { resultados na associação } \\
\text { com predinisona; } \\
\text { inibição de HPA no rim e } \\
\text { regulando a expressão } \\
\text { de nefrina. }\end{array}$ \\
\hline $\begin{array}{l}\text { Chih } \\
\text { et al } \\
(2012)\end{array}$ & $\begin{array}{c}\text { Hibiscus sabdariffa } \\
\text { \& Alopurinol }\end{array}$ & $\begin{array}{l}\text { Hiper-uricemia } \\
\text { por ácido oxônico } \\
280 \mathrm{mg} / \mathrm{kg}\end{array}$ & $\begin{array}{l}\text { Na ração: } 5 \text { sem. Sprague } \square \text { Dawley } \\
\text { Grupo I: salina (saudáveis) } \\
\text { Grupo II: modelo } \\
\text { Grupo II: alopurinol (10mg/kg) } \\
\text { Grupo IV: } 1 \% \text { de HSE } \\
\text { Grupo V: } 2 \% \text { HSE } \\
\text { Grupo VI: } 5 \% \text { HSE }\end{array}$ & $\begin{array}{l}\text { Ácido úrico e creatinina } \\
\text { sérica; } \\
\text { Xantina oxidase } \\
\text { Atividade de uricase }\end{array}$ & $\begin{array}{l}\text { HSE conseguiu diminuir } \\
\text { ácido úrico aumentando } \\
\text { a atividade da enzima } \\
\text { uricase catalase. }\end{array}$ \\
\hline $\begin{array}{l}\text { Meng } \\
\text { et al } \\
(2007)\end{array}$ & $\begin{array}{c}\text { Astragalus } \\
\text { membranaceus } \\
\text { mongholicus e } \\
\text { Angelica sinensis }\end{array}$ & $\begin{array}{l}\text { Obstrução } \\
\text { unilateral do } \\
\text { ureter (UUO) }\end{array}$ & $\begin{array}{l}\text { Gavagem: } 10 \text { dias Wistar } \\
\text { Grupo Sham água destilada. } \\
\text { Grupo UUO: água destilada } \\
\text { Grupo UAA: } 14 \mathrm{~g} / \mathrm{kg} / \mathrm{dia}\end{array}$ & $\begin{array}{l}\text { Histopatologia renal, } \\
\text { Angiotensina II, } \\
\text { ET1;(NOS);(NO); } \\
\text { (ROS). }\end{array}$ & $\begin{array}{l}\text { O efeito antifibrótico das } \\
\text { pela maior produção } \\
\text { de NO pela ativação de } \\
\text { NOS diminuição de ROS }\end{array}$ \\
\hline
\end{tabular}


TABELA 1. Resumo da pesquisa relacionando lesão renal, ervas e medicina chinesa.

\begin{tabular}{|c|c|c|c|c|c|}
\hline $\begin{array}{c}\text { Ding } \\
\text { et al } \\
(2013)\end{array}$ & $\begin{array}{c}\text { Sanqi Oral Liquid: } \\
\text { \& CAO: coated } \\
\text { aldehyde } \\
\text { oxygenstarch }\end{array}$ & $\begin{array}{l}\text { Nefrectomia rim } \\
\text { direito e ablação } \\
\text { de } 2 / 3 \text { do rim } \\
\text { esquerdo }\end{array}$ & $\begin{array}{l}\text { Gavagem: } 12 \text { sem Sprague-Dawley } \\
\text { Normal (saudáveis): } 4 \mathrm{ml} \text { salina } \\
\text { Modelo: } 4 \mathrm{ml} \text { salina } \\
\text { CAO: } 4 \mathrm{ml}[1.7 \mathrm{~g}] \text { CAO + salina } \\
\text { THD: } 4 \mathrm{ml} \text { Sanqi }[6,7 \mathrm{~g} / \mathrm{kg} / \text { dia] } \\
\text { TMD: } 2 \mathrm{ml} \text { Sanqi }[6,7 \mathrm{~g} / \mathrm{kg} / \mathrm{dia}]+2 \mathrm{ml} \text { salina } \\
\text { TLD: } 1 \mathrm{ml} \text { Sanqi }[6,7 \mathrm{~g} / \mathrm{kg} / \mathrm{dia}]+3 \mathrm{ml} \text { de } \\
\text { salina }\end{array}$ & $\begin{array}{l}\text { Ureia e creatinina sérica; } \\
\text { Contagem plaquetária, } \\
\text { CD4+, CD8+, CD68+e } \\
\text { Histopatologia renal }\end{array}$ & $\begin{array}{l}\text { Sanqi tem efeito } \\
\text { significativo na regulação } \\
\text { dos subprodutos dos } \\
\text { linfócitos T reduzindo a } \\
\text { infiltração de macrófagos } \\
\text { nos tecidos renais e } \\
\text { diminuindo a fibrose } \\
\text { tubulointersticial. }\end{array}$ \\
\hline $\begin{array}{l}\text { Zuo } \\
\text { et al } \\
(2013)\end{array}$ & $\begin{array}{l}\text { Liriope spicarta var. } \\
\text { polifera (LSP) } \\
\text { Cloridrato de } \\
\text { Metformina }\end{array}$ & $\begin{array}{l}\text { Nefropatia } \\
\text { diabética: dieta } \\
\text { modificada }\end{array}$ & $\begin{array}{l}\text { Gavagem: } 28 \text { dias Wistar } \\
\text { Grupo normal: água destilada (veículo) } \\
\text { Grupo controle diabetes: veículo } \\
\text { Cloridrato de Metformina: veículo + } \\
\text { 150mg/kg] } \\
\text { LSP 400mg: veículo + LSP } \\
\text { LSP 200mg: // e LSP 100mg: // }\end{array}$ & $\begin{array}{l}\text { Glicemia de jejum, } \\
\text { hemoglobina glicosada; } \\
\text { Creatinina e ureia sérica; } \\
\text { (SOD);(MDA), (CAT)e } \\
\text { (GSH -px). } \\
\text { Proteína, creatinina } \\
\text { urinária e clearance de } \\
\text { creatinina. Histopatologia } \\
\text { renal e Determinação de } \\
\text { AGE; }\end{array}$ & $\begin{array}{l}\text { LSP: melhora pela } \\
\text { Hipolipidemia, } \\
\text { antioxidação e supressão } \\
\text { do sistema AGE/RAGE }\end{array}$ \\
\hline
\end{tabular}

das pesquisas chinesas sobre a química dos produtos naturais em 2011, afirma que os estudos realizados no país ofereceram uma alternativa metodológica para o pensamento convencional de isolamento e análise estrutural de componentes individuais; propondo a investigação da influência de grupos de componentes sobre todo o organismo. E ainda, que esses trabalhos pioneiros apresentam metodologia sólida para a realização de estudos com base em análises químicas e mecanismos de ação farmacológicos dos fitoterápicos usados pela MTC.

Em diversos estudos, os medicamentos alopáticos agiram como controle. Gao et al (2010) comparou os efeitos e mecanismos de ação da Sinvastatina e do Ruibarbo na nefropatia diabética em ratos geneticamente modificados. Os resultados demonstraram que o Ruibarbo obteve melhores resultados, pois além de reduzir colesterol, triglicérides, LDL e apolipoproteína E como a Sinvastatina, somente a erva conseguiu amenizar as alterações morfopatológicas renais, aumento do glomérulo, proliferação de matriz extracelular e modular as expressões de TGF- $\beta$ e fibronectina.

O modelo de lesão renal mais adotado foi a de nefrotoxicidade induzida pelo antibiótico adriamicina, quimioterápico empregado no tratamento de câncer desde a década de 60 (Yilmaz et al, 2006) .

Em seu estudo Wu etal (2012) demonstraram que a injeção intraperitoneal de gentamicina com $100 \mathrm{mg} / \mathrm{kg}$ aumenta os níveis plasmáticos de ureia, creatinina, óxido nítrico. Além de provocar necrose nos túbulos dos córtex renais.

A nefrectomia em ratos resulta em glomerulonecrose, lesão tubulointersticial e proteinúria, reações semelhantes aos provocados pela hipertensão arterial, estresse oxidativo e alterações lipídicas em humanos (Remuzzi et al, 2006).

Os ratos nefrectomizados de Chan et al
(2013) apresentaram maiores níveis séricos de ureia e creatinina; além de proteinúria, hiperlipidemia e aumento no estresse oxidativo quando comparados com o grupo saudável.

A gavagem foi o método de administração de medicamentos em 10 dos 12 estudos. Esse método permite o controle de forma confiável da quantidade de drogas que cada animal ingere.

Na maioria dos estudos a amostra continha grupos de ratos saudáveis, modelo (com lesão renal e sem tratamento) e tratamento composto por doses diferentes do mesmo fitoterápico e/ou animais tratados com medicamentos alopáticos.

Yue et al (2013) testou duas doses de Abelmoschus manihot em ratos que sofreram nefrectomia no rim direito e nefrotoxicidade no rim esquerdo. Apenas a dose alta atenuou os efeitos nefrotóxicos da adriamicina.

Na metodologia de Chen et al (2013) os 50 ratos da espécie Sprague-Dawley foram divididos em 5 grupos, sendo: o grupo controle, ratos saudáveis; grupo TRA de corrida tradicional, MOD de corrida com aumento de temperatura, umidade e sons ambientes modificados, grupo LOS recebeu losartan e o grupo $\mathrm{CHI}$ que recebeu Yishen Huanji. Os grupos LOS e CHI também completaram a rotina de exercícios modificada e os medicamentos foram administrados por gavagem. Os grupos tratados obtiveram resultados de proteção renal, porém apenas o grupo da erva chinesa reduziu a angiotensina II renal.

Em onze estudos selecionados os medicamentos fitoterápicos conseguiram melhorar ou prevenir a lesão renal.

No estudo de Wen et al (2013) o fitoterápico Yiqiyangiyin não conseguiu amenizar os efeitos da nefropatia induzida por adriamicina em ratos, somente a predinisona e a combinação da erva com o medicamento obtiveram a melhora esperada. Os autores sugerem a associação das duas terapias

Rev. Bras. PI. Med., Campinas, v.17, n.4, supl. III, p.1192-1198, 2015. 
com base nos resultados apresentados no trabalho.

Segundo Bruning et al (2012) a fitoterapia pode ser utilizada como recurso complementar nos tratamentos alopáticos desde que sejam consideradas as possíveis interações e reações adversas. E ainda é preciso que os profissionais da saúde que fazem uso desse recurso estejam cientes dos medicamentos utilizados pelos pacientes e que tenham o conhecimento necessário para indicação das ervas.

Os mecanismos de ação das ervas foi alvo de interesse em diversos artigos. Alteração na expressão genética de nefrina, modulação do sistema renina - angiotensina renal, efeitos antioxidantes e modulação na produção de óxido nítrico parecem ser os principais responsáveis por esses benefícios.

\section{CONCLUSÃO}

As lesões renais constituem um problema de saúde que desperta interesse mundial e a busca por tratamentos eficazes e mais baratos que amenizem e sanem as morbidades e co-morbidades decorrentes das injúrias renais são objetivos de grandes centros de pesquisa.

A fitoterapia pode atuar como terapia complementar no tratamento dessas lesões, pois é um recurso terapêutico de baixo custo e que pode ser associado a intervenções alopáticas. Porém, é preciso conhecer profundamente os riscos, as possíveis interações, toxicidade, mecanismos de ação e efeitos adversos do uso dessas ervas.

A partir dessa necessidade, as pesquisas com fitoterápicos orientais cresceram consideravelmente nos últimos anos, em parte pela disponibilidade de tecnologia mais avançada e pela evidente aproximação da Medicina Tradicional Chinesa à Medicina Ocidental. Esse intercâmbio gera benefício para ambos, pois ao mesmo tempo difunde os conhecimentos do uso das ervas medicinais e elucida questões a respeito da elaboração e funcionamento das fórmulas milenares.

\section{REFERÊNCIAS}

ANDRADE, J.T.; DA COSTA, L.F.A. Complementar no SUS: práticas integrativas sob a luz da Antropologia médica. Saúde e Sociedade São Paulo. v.19, n.3, p.497-508, 2010.

BRASIL, Ministério da Saúde. Secretaria de Atenção à Saúde. Departamento de Atenção Básica. Política Nacional de Práticas Integrativas e Complementares no SUS - PNPIC-SUS. Brasília: Ministério da Saúde, 2006.

BRUNING, M.C.R.; et al. A utilização da fitoterapia e de plantas medicinais em unidades básicas de saúde nos municípios de Cascavel e Foz do Iguaçu $\square$ Paraná: a visão dos profissionais de saúde. Ciência \& Saúde Coletiva, v.17, n.10, p.2675-2685, 2012.

CHAN, H. P et al. Rokumi-jio-gan-containing prescriptions regulate oxidative stress through improving dyslipidemia in a subtotal nephrectomized rat model. Journal of Ethnopharmacology v.148, p.449-458, 2013.

CHEN, H.; et al. . A modified rat model of exercise-induced renal injury and the protective effects of losartan and Yishen Huanji decoction. Renal Failure, v. 35, n.7, p.951-957, 2013.

$\mathrm{CHIH}$, Y.K. et al. Hibiscus sabdariffa L. extracts reduce serum uric acid levels in oxonate-induced rats. Journal of Functional Foods, v.4, p. 375-381, 2012.

COCA, S.G. et al. Long-term Risk of Mortality and Other Adverse Outcomes After Acute Kidney Injury: A Systematic Review and Meta-analysis. American Journal Kidney Diseases, v.53, n.6, p. 961-973, 2009.

DING, H.M et al. Effect of Sanqi Oral Liquid on the Expressions of CD4+, CD8+ and CD68+ Rats with Chronic Renal Failure Cells in 5/6 Nephrectomized. Chinese Journal of Integrative Medicine,v.19, n.8, p.589-595,2013.

ERWEI, L. et al. Eucommia ulmoides Bark Protects Against Renal Injury in Cadmium-Challenged Rats. Journal of Medicinal Food, v.15, p.307-314, 2012.

GAO, Q. et.al. Rhein Improves Renal Lesion and Ameliorates Dyslipidemia in $\mathrm{db} / \mathrm{db}$ Mice with Diabetic Nephropathy. Planta Medica v. 76, p. 27-33, 2010.

HARRIS, P.E.; et al. Prevalence of complementary and alternative medicine (CAM) use by the general population: a systematic review and update. International Journal of Clinical Practice. v.66, n.10, p. 924-939, 2012.

$\mathrm{HE}$, L. et al. Amelioration of anti-cancer agent adriamycininduced nephrotic syndrome in rats by Wulingsan (GoreiSan), a blended traditional Chinese herbal medicine. Food and Chemical Toxicology v.46, p.1452-1460, 2008.

HUANG, J. et al. Effects of Genistein, Apigenin, Quercetin, Rutin and Astilbin on serum uric acid. Food and Chemical Toxicology v.49, p. 1943-1947, 2011.

LAM, T.P.; SUN, K.S. Dilemma of integration with Western medicine -Views of Traditional Chinese Medicine practitioners in a predominant Western medical setting. Complementary Therapies in Medicine v.21, p.300305, 2013.

LI, S. et al. Herb network construction and co-module analysis for uncovering the combination rule of traditional Chinese herbal formulae. Bio Med Central Bioinformatics v.11, p.1-12, 2010.

LO,DER CHENG. Fórmulas magistrais Chinesas. 1.ed. São Paulo: Roca, 2008. 590p.

MACIOCIA G. Fundamentos da Medicina Tradicional Chinesa. 2.ed. São Paulo: Roca, 2007. 967p.

MENG, L. et al. A combination of Chinese herbs, Astragalus membranaceus var. mongholicus and Angelica sinensis, enhanced nitric oxide production in obstructed rat kidney Vascular Pharmacology, v.47, p.174-183, 2007.

REMUZZI, G et.al. Mechanisms of progression and regression of renal lesions of chronic nephropathies and diabetes. Journal of Clinical Investigation v.116, p.288-296, 2006.

SHAO, L.; ZHANG, B. Traditional Chinese medicine 
network pharmacology: theory, methodology and application. Chinese Journal of Natural Medicines. v.11, n.2, P.110-120, 2013.

SUCHER, N.J. The application of Chinese medicine to novel drug discovery. Expert Opinion on Drug Discovery v.8, p.21-34, 2013.

TAO LI, P.K.; BURDMANN, E,A, \& MEHTA, R.L. Injúria Renal Aguda: um alerta global. Jornal Brasileiro de Nefrologia. v.35, n.1, p.1-5, 2013.

WEN, S. et.al.. Effect of Yiqiyangyin recipe on heparanase and nephrin in rats with adriamycininduced nephropathy. Journal of Traditional Chinese Medicine, v.33, n.3, p.334-342, 2013.

Who - World Health Organization.Traditional Medicine Strategy 2002 - 2005. Geneva, 2002. 74p.

WU, G. et.al. Nephroprotective activity of Macrothelypteris oligophlebia rhizomes ethanol extract. Pharmaceutical Biology, v.50, n.6, p.773777, 2012.

YANG, Y. et.al. Natural products chemistry research: progress in China in 2011. Chinese Journal of Natural Medicines v.11, n.2, p. 97-109, 2013.

YAO, Y. et al. Deciphering the combination principles of Traditional Chinese Medicine from a systems pharmacology perspective based on Ma-huang Decoction. Journal of Ethnopharmacology. v. 150; p. 619-638, 2013.

YILMAZ, S. et.al. Protective effect of lycopene on adriamycin-induced cardiotoxicity and nephrotoxicity. Toxicology v.218, p.164-171, 2006.

YUE, T. et al. Huangkui capsule, an extract from Abelmoschus manihot (L.) medic, ameliorates adriamycin-induced renal inflammation and glomerular injury via inhibiting p38MAPK signaling pathway activity in rats. Journal of Ethnopharmacology v.147, p.311-320, 2013.

ZUO-QI, X. et. al. Preventive effects of polysaccharides from Liriope spicata var. prolifera on diabetic nephropathy in rats Internationtal Journal of Biological Macromolecules. n.63 p.114 - 120, 2013. 